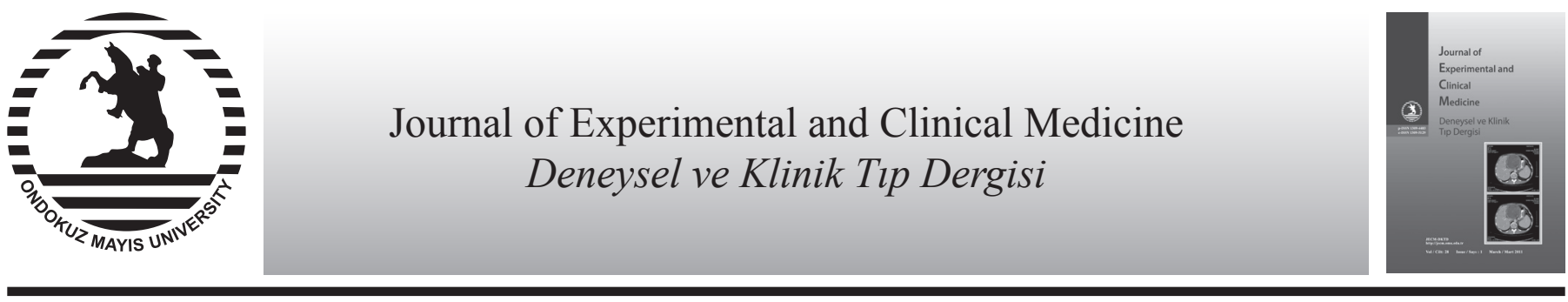

Case Report

\title{
Allergic concact dermatitis from chamomile plant
}

\author{
Müge Güler Özden, *Hilal Denizli, Fatma Aydın, Nilgün Şentürk, Tayyar Cantürk, Ahmet Yaşar Turanlı \\ Department of Dermatology, Medical Faculty, Ondokuz Mayis University, Samsun, Turkey
}

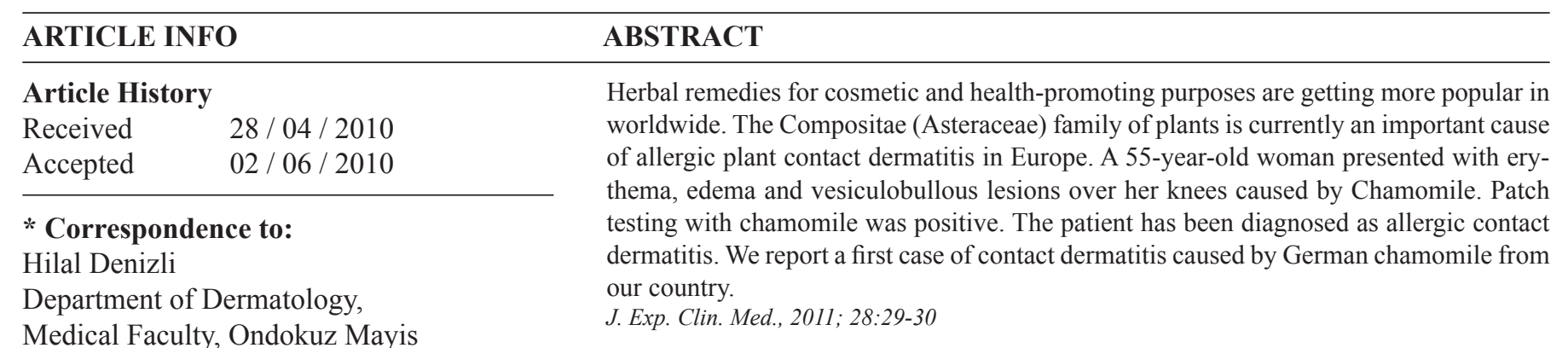

University, Samsun, Turkey

e-mail:hilaldenizli@hotmail.com

\section{Keywords:}

Allergic contact dermatitis

Chamomile

Herbal

Patch test

Compositae

Astraceae

\section{Introduction}

In recent years, the demand for cosmetics containing botanical extract has dramatically increased due to their pleasing fragrance and the perception that these products are safer than the synthetic products (Corazza et al., 2009). Together with this tendency, reports of adverse effects, including allergic contact dermatitis, urticaria and anaphylactic reactions from plant constituents have been rapidly emerged. The daisy family (Asteraceae, Compositae), is an important allergenic plant family in Europe. Although the relevance of other plants (e.g. tea-tree oil) has been well demonstrated, allergic dermatitis caused by compositae is less reported (Paulsen, 2002).

\section{Case Report}

A 55-year-old Caucasian woman suffering from itchy lesions presented to our department with erythema, edema and vesiculobullous lesions over her knees. She had applied Chamomile plant directly to her knees to relieve joint pain, 5 days earlier. On dermatological examination, there were erythema, edema and vesiculobullous lesions over her patellae (Fig. 1).

She was treated with oral Loratadine $10 \mathrm{mg}$ /day combined with topical corticosteroid. Four days later, the lesions resisted and systemic corticosteroid was administered. The lesions started to heal, leaving slight post-inflammatory hyperpigmentation. One month later, patch testing was performed

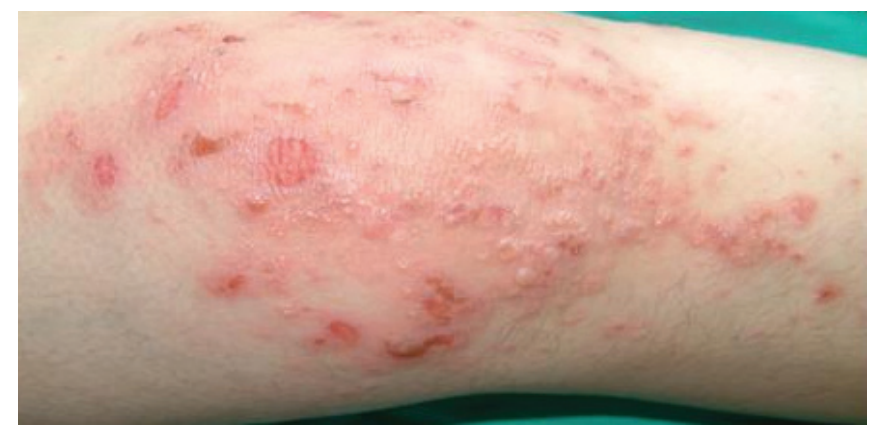

Fig. 1. Erythema, edema and vesiculobullous lesions over her patellae.

with a European standard series and chamomile that she had used before. There was a +++ reaction to the chamomile only, no reaction being seen to other allergens in the standard series. The same application of chamomile plant was negative on patch testing in 15 control subjects.

\section{Discussion}

Plants and their products cause a variety of adverse cutaneous reactions, including the vast majority of cases of allergic contact dermatitis. Corazza et al. showed that $60.25 \%$ of dermatological out-patient population reported the use of natu- 
ral topical products and $6.22 \%$ of them referred one or more adverse cutaneous reactions (Corazza et al., 2009). Hausen et al., indicated the vernacular name 'chamomile' has been used interchangeably for at least 3 different species, namely German chamomile [Chamomilla recutita (L.) Rauschert], Roman chamomile [Chamaemelum nobile (L.) All.] and dog fennel [Anthemis cotula L.]. German and Roman chamomile are both important medicinal plants. Chamomile has experimentally supported effects such as anti-inflammatory, spasmolytic, wound-healing and sedative/anxiolytic and is also used in 'natural' cosmetics and herbal teas (Paulsen, 2002).
Recurrent facial dermatitis, systemic contact dermatitis and anaphylactic reaction from chamomile tea have been reported (Rodríguez-Serna, 1998; Rycroft, 2003). Compositaeallergic persons should be warned against topical and oral use of Compositae-containing products, not only because of contact dermatitis, but also because of anaphylactic reactions. Besides, patients sensitized to camomile are also sensitized to mugwort (Andres et al., 2009). Therefore, it is important to inform the patients against the mugwort and pollen-derived food allergens, based on a high incidence of allergic cross-. reactivity (Andres et al., 2009).

\section{REFERENCES}

Andres, C., Chen, W.C., Ollert, M., Mempel, M., Darsow, U., Ring, J. 2009. Anaphylactic Reaction to Chamomile Tea. Allergol. Int. 58, 135136.

Corazza, M., Borghi, A., Lauriola, M.M., Virgilli, A. 2009. Use of topical herbal remedies and cosmetics: a questionnaire-based investigation in dermatology out patients. J. Eur. Acad. Dermatol. Venerol. 23,1298-1303.

Paulsen, E., 2002. Contact sensitization from Compositae-containing herbal remedies and cosmetics. Contact Dermatitis. 47, 189-198.

Rycroft, R., 2003. Recurrent facial dermatitis from chamomile tea. Contact Points. 48, 229.

Rodríguez-Serna, M., Sánchez-Motilla, J.M., Ramón, R., Aliaga, A., 1998. Allergic and systemic contact dermatitis from Matricaria chamo milla tea. Contact Dermatitis. 39, 192-193. 